\title{
OPEN Insights into cell robustness against lignocellulosic inhibitors and insoluble solids in bioethanol production processes
}

\author{
Antonio D. Moreno ${ }^{2}$, Cristina González-Fernández ${ }^{1} \&$ Elia Tomás-Pejón ${ }^{1 凶}$
}

Increasing yeast robustness against lignocellulosic-derived inhibitors and insoluble solids in bioethanol production is essential for the transition to a bio-based economy. This work evaluates the effect exerted by insoluble solids on yeast tolerance to inhibitory compounds, which is crucial in high gravity processes. Adaptive laboratory evolution (ALE) was applied on a xylose-fermenting Saccharomyces cerevisiae strain to simultaneously increase the tolerance to lignocellulosic inhibitors and insoluble solids. The evolved strain gave rise to a fivefold increase in bioethanol yield in fermentation experiments with high concentration of inhibitors and $10 \%(\mathrm{w} / \mathrm{v})$ of water insoluble solids. This strain also produced $5 \%(P>0.01)$ more ethanol than the parental in simultaneous saccharification and fermentation of steam-exploded wheat straw, mainly due to an increased xylose consumption. In response to the stress conditions (solids and inhibitors) imposed in ALE, cells induced the expression of genes related to cell wall integrity (SRL1, CWP2, WSC2 and WSC4) and general stress response (e.g., $C D C 5, D U N 1, C T T 1, G R E 1)$, simultaneously repressing genes related to protein synthesis and iron transport and homeostasis (e.g., FTR1, ARN1, FRE1), ultimately leading to the improved phenotype. These results contribute towards understanding molecular mechanisms that cells might use to convert lignocellulosic substrates effectively.

Lignocellulose is present in agricultural residues such as rice straw, wheat straw, olive pruning, and gardening wastes. It is a renewable energy reservoir and a sustainable feedstock for chemicals and fuels. The efficient use of lignocellulosic resources will significantly boost the transition towards a bio-based economy. In this sense, the extensive research progress during the last decades has promoted the construction of several industrial-scale plants for lignocellulosic ethanol production ${ }^{1}$. Conversion of lignocellulose under high gravity conditions (i.e., high substrate concentrations) is crucial to achieve high ethanol titers and reduce distillation costs. However, high-gravity technology is still very challenging due to the increase in complexity of the corresponding medium (insoluble solids, inhibitors, etc.). These difficulties associated to the use of high substrate loadings negatively influence cell performance during the fermentation.

Biotechnological conversion of lignocellulose into bioethanol involves pretreatment, enzymatic hydrolysis, fermentation and product recovery as major steps. Pretreatment is required to alter the physicochemical properties of lignocellulosic biomass and ease the accessibility of the hydrolytic enzymes to carbohydrates. Most common pretreatment technologies lead, however, to biomass degradation and formation of several compounds, which may inhibit the subsequent saccharification and fermentation steps. In particular, the effects that these inhibitory compounds exert on yeast have been widely explored ${ }^{2-5}$, and many different studies have targeted the overcoming of such effects ${ }^{6-9}$.

Along with the inhibitors, insoluble solids are also present in the media during simultaneous saccharification and fermentation (SSF) and consolidated bioprocesses (CBP). These configuration strategies have been claimed as two promising options to produce lignocellulosic ethanol due to the costs saving potential resulting from the integration of the saccharification and fermentation steps. The integration of these stages reduces the required equipment, decreases the overall process length, and increases the fermentation efficiency ${ }^{10,11}$. However, the presence of insoluble solids may also influence the fermentation performance of yeast cells as well as yeasts tolerance to inhibitory compounds ${ }^{12}$, especially at the initial fermentation stages when the concentration of solids

${ }^{1}$ Biotechnological Processes Unit, IMDEA Energy Institute, Avda. Ramón de la Sagra 3, 28935 Móstoles, Madrid, Spain. ${ }^{2}$ Advanced Biofuels and Bioproducts Unit, CIEMAT, Avda. Complutense 40, 28040 Madrid, Spain. ${ }^{\square}$ email: elia.tomas@imdea.org 
is high (solids concentration is diminished along the time due to enzymatic hydrolysis of carbohydrates). In the particular case of CBP processes, hydrolysis of cellulose usually exhibits low rates ${ }^{13}$, thus implying the presence of insoluble solids at high concentrations for longer periods than in SSF.

Solid insoluble particles produce shear stress, induce damage in brewing yeast, promote changes in gene expression and accumulation of intracellular reactive oxygen species ${ }^{12,14}$. Notwithstanding, the potential effects that insoluble solids have on bioethanol producing yeasts have been frequently underestimated. Several studies have demonstrated the tolerance of yeast cells towards lignocellulose-derived inhibitors during fermentation of liquid prehydrolysates while the same concentration of inhibitory products completely inhibited cells in SSF processes $^{15,16}$. Thus, determining the impact of insoluble solids on yeasts is therefore crucial to identify future research lines for the development of more robust and efficient strains with potential applications at industrial scale.

The present work aims at evaluating the effect exerted by insoluble solids on the tolerance of yeast cells to inhibitory compounds, which is of great relevance in SSF/CBP processes at high gravity. For this purpose, the fermentation performance of the yeast Saccharomyces cerevisiae F12, a recombinant xylose-fermenting strain successfully used in SSF processes ${ }^{8,10}$, was investigated in presence and absence of lignocellulosic insoluble solids and/or inhibitors to determine its tolerance towards these stressors. Since, adaptive laboratory evolution (ALE) is effective for obtaining novel yeast strains better adapted to the challenging bioethanol production conditions $^{8,17-19}$, S. cerevisiae F12 was subjected to an ALE procedure in the presence of both lignocellulosic degradation compounds and insoluble solids. Subsequently, the genetic changes for facing such challenging environment were identified. In evolutionary procedures, cells are forced to replicate under certain restricting conditions during long periods of time. The modulation of the environment during evolution increases the rate of spontaneous mutagenesis and so, designing an appropriated evolution strategy is crucial for the success of the process.

Overall, this study reports for the first time the evolution of yeast cells on insoluble solids and inhibitors to better adapt them to high gravity technology. This work also reveals the most important variations in gene expression that take place during the evolution process. Results presented herein will pave the way for identifying new strategies to develop novel strains to be efficiently applied in high-gravity lignocellulosic conversion processes (i.e., with inhibitors and insoluble solids) at the industrial scale.

\section{Materials and methods}

Insoluble solids from steam-exploded wheat straw. The collection of the used wheat straw complied with relevant institutional, national, and international guidelines and legislation. Wheat straw was pretreated in a 10 -L steam explosion reactor at $210^{\circ} \mathrm{C}$ for $5 \mathrm{~min}$. Slurry was separated into liquid fraction and water insoluble solid (WIS) fraction by vacuum filtration using a Büchner funnel. The resulting WIS fraction was thoroughly washed with distilled water to remove soluble inhibitory compounds and embedded sugars. The WIS fraction had the following composition in terms of \% dry weight (w/w): 52.1 cellulose, 8.0 xylan, 0.2 arabinose and 33.9 lignin.

In order to assess the effect of solids on yeast fermentation, one portion of WIS was dried at $40{ }^{\circ} \mathrm{C}$ and added at $5 \%(\mathrm{w} / \mathrm{v})$ and $10 \%(\mathrm{w} / \mathrm{v})$ to the synthetic fermentation media depending on the experimental conditions. Both the whole slurry and the WIS fraction were used as substrate for SSF experiments.

Inhibitor mix. The inhibitor mix was prepared by using commercial compounds to give a final composition equivalent to those commonly found in steam-exploded lignocellulosic hydrolysates $(2.1 \mathrm{~g} / \mathrm{L}$ furfural, $0.3 \mathrm{~g} / \mathrm{L}$ 5-HMF, $13.4 \mathrm{~g} / \mathrm{L}$ acetic acid, $10.5 \mathrm{~g} / \mathrm{L}$ formic acid, $0.4 \mathrm{~g} / \mathrm{L}$ ferulic acid, $0.2 \mathrm{~g} / \mathrm{L}$ syringaldehyde, and $0.1 \mathrm{~g} / \mathrm{L}$ vanillin $)^{20}$. This inhibitor mix was used as selection pressure during the evolutionary engineering approach and in fermentation experiments at $50 \%(\mathrm{v} / \mathrm{v})$, and $100 \%(\mathrm{v} / \mathrm{v})$ dilution in presence and absence of WIS.

Microorganism and cell propagation. Recombinant S. cerevisiae F12 was kindly supplied by Professor Lisbeth Olsson from Chalmers University of Technology (Sweden). This strain was genetically modified to consume xylose by overexpressing the endogenous gene encoding xylulokinase and by introducing genes encoding xylose reductase and xylitol dehydrogenase from Scheffersomyces stipitis ${ }^{21}$.

For preinoculum preparation, S. cerevisiae F12 cells were grown in 100 -mL shake flasks with $20 \mathrm{~mL}$ YPD medium (10 g/L yeast extract, $20 \mathrm{~g} / \mathrm{L}$ peptone, $20 \mathrm{~g} / \mathrm{L}$ glucose $)$ in an orbital shaker at $150 \mathrm{rpm}$ and $32^{\circ} \mathrm{C}$ for $16 \mathrm{~h}$. Cells were harvested by centrifugation $\left(3000 \mathrm{~g}, 8 \mathrm{~min}, 25^{\circ} \mathrm{C}\right)$ and diluted with the corresponding medium to get the appropriate inoculum size.

Adaptive laboratory evolution experiment. S. cerevisiae F12 was subjected to ALE to increase its robustness towards lignocellulose-derived inhibitors and insoluble solids. ALE was performed by sequential batch cultivation of yeast cells in 250-mL Erlenmeyer flasks containing $50 \mathrm{~mL}$ of the corresponding medium. Cells were incubated at $150 \mathrm{rpm}, 32{ }^{\circ} \mathrm{C}$ and $\mathrm{pH} 5.0$ with an initial $\mathrm{OD}_{600}$ of 0.1 . YNB (Conda, Cat.1553.00) supplemented with $7.5 \mathrm{~g} / \mathrm{L}\left(\mathrm{NH}_{4}\right)_{2} \mathrm{SO}_{4}$ was used as basal medium. ALE experiment was distributed in different stages according to Table 1. 4-mm diameter glass beads (Hecht Karl $\left.{ }^{\mathrm{TN}} 1401 / 4\right)$ were used as insoluble solids to progressively evolve cells and facilitate their subsequent recovery. The experiment started by adding $20 \%$ $(\mathrm{w} / \mathrm{w})$ insoluble solids to a medium containing glucose and xylose at a final concentration of $10 \mathrm{~g} / \mathrm{L}$ each. The xylose:glucose ratio (w:w) increased gradually to $10: 10,15: 5$, and 18:2 as evolution proceeded. Simultaneously, solids were combined with increased concentrations of the inhibitory mix, starting from $12.5 \%(\mathrm{v} / \mathrm{v}$ ) to $80 \%$ $(\mathrm{v} / \mathrm{v})$. 


\begin{tabular}{|c|c|c|c|c|}
\hline Round No & Solids \% (w/v) & Xylose:Glucose (g/L) & Inhibitors \% (v/v) & $\mathrm{N}^{0}$ of rounds* \\
\hline \multirow[t]{11}{*}{ Round 0} & 20 & $10: 10$ & 0 & 2 \\
\hline & 20 & $15: 5$ & 12.5 & 7 \\
\hline & 20 & $15: 5$ & 15 & 2 \\
\hline & 20 & $15: 5$ & 17.5 & 4 \\
\hline & 20 & $15: 5$ & 20 & 2 \\
\hline & 20 & $15: 5$ & 22.5 & 5 \\
\hline & 20 & $15: 5$ & 25 & 13 \\
\hline & 20 & $15: 5$ & 27.5 & 11 \\
\hline & 20 & $18: 2$ & 30 & 2 \\
\hline & 20 & $18: 2$ & 50 & 8 \\
\hline & 20 & $18: 2$ & 70 & 4 \\
\hline Round 88 & 20 & $18: 2$ & 80 & 4 \\
\hline
\end{tabular}

Table 1. Strategy followed during the ALE in terms of insoluble solids, xylose:glucose and inhibitors concentration for each round. ${ }^{*}$ Number of rounds under each condition.

\begin{tabular}{|l|l|l|}
\hline Assay & Inhibitor mix \% (v/v) & WIS \% (w/v) \\
\hline CONTROL & 0 & 0 \\
\hline I50 & 50 & 0 \\
\hline I100 & 100 & 0 \\
\hline WIS5 & 0 & 5 \\
\hline WIS10 & 0 & 10 \\
\hline I50_WIS5 & 50 & 5 \\
\hline I50_WIS10 & 50 & 10 \\
\hline I100_WIS5 & 100 & 5 \\
\hline I100_WIS10 & 100 & 10 \\
\hline
\end{tabular}

Table 2. Concentration of inhibitors and/or WIS during fermentation assays.

Selection of spontaneous mutants with improved tolerance was based on increased specific growth rates. When an improvement in the yeast growth was detected (measured as $\mathrm{OD}_{600}$ basis), xylose:glucose ratio and inhibitor concentration in the evolution media was increased (Table 1). Each round of evolution started by inoculating an aliquot of cells from the previous shake flask culture at a final $\mathrm{OD}_{600}$ of 0.1 . The evolved strain was obtained after 88 rounds of evolutions $(\approx 2.200$ generations). For isolation of single colonies, cells from the final round were harvested, diluted accordingly, and grown for $36 \mathrm{~h}$ at $32{ }^{\circ} \mathrm{C}$ in a YPXD-agar plate containing $10 \mathrm{~g} / \mathrm{L}$ glucose, $10 \mathrm{~g} / \mathrm{L}$ xylose and $20 \mathrm{~g} / \mathrm{L}$ agar. One of the most prominent colonies was selected and named as evolved S. cerevisiae F12 strain.

Fermentation tests. Synthetic fermentation media containing $10 \mathrm{~g} / \mathrm{L}$ glucose, $10 \mathrm{~g} / \mathrm{L}$ xylose, $2 \mathrm{~g} / \mathrm{L} \mathrm{NH}_{4} \mathrm{Cl}$, $2 \mathrm{~g} / \mathrm{L} \mathrm{KH}_{2} \mathrm{PO}_{4}, 0.3 \mathrm{~g} / \mathrm{L} \mathrm{MgSO}{ }_{4} \cdot 7 \mathrm{H}_{2} \mathrm{O}$, and $5 \mathrm{~g} / \mathrm{L}$ yeast extract were used to assess the fermentation performance of $S$. cerevisiae F12 in presence of WIS and/or inhibitors under the conditions stated in Table 2. Fermentation tests were carried out in triplicate in sterilized 250-mL Erlenmeyer flasks with $100 \mathrm{~mL}$ medium at $150 \mathrm{rpm}$ and $32{ }^{\circ} \mathrm{C}$ for $48 \mathrm{~h}$ with $1 \mathrm{~g} / \mathrm{L}$ (dry weight) of inoculum concentration.

In a first set of experiments, the influence of lignocellulosic degradation compounds on parental S. cerevisiae F12 was evaluated by using $50 \%$ and $100 \%$ (v/v) of the inhibitor mix. Subsequently, the effect exerted by solids on the fermentation performance of yeast cells was assessed by adding $5 \%$ and $10 \%$ of WIS (w/v). Finally, cells were subjected to fermentation in the presence of different combinations of solids ( $5 \%$ and $10 \% \mathrm{WIS}(\mathrm{w} / \mathrm{v})$ ) and inhibitors $(50 \%$ and $100 \%(\mathrm{v} / \mathrm{v})$ of the inhibitor $\mathrm{mix})$ to identify any potential synergism between these two stressors.

Evolved S. cerevisiae F12 strain was also used under the most sever conditions: i) the presence of 100\% (v/v) inhibitor mix, ii) the presence of $10 \%$ of WIS (w/v) and, iii) the combination of both $100 \%(\mathrm{v} / \mathrm{v})$ inhibitors and $10 \%$ of WIS $(\mathrm{w} / \mathrm{v})$.

Simultaneous saccharification and fermentation assays. Parental and evolved S. cerevisiae F12 strains were used in SSF with steam-pretreated wheat straw at high substrate loadings to evaluate the success of the evolutionary engineering approach. For that, the whole slurry supplemented with nutrients $\left(2 \mathrm{~g} / \mathrm{L} \mathrm{NH}_{4} \mathrm{Cl}\right.$, $2 \mathrm{~g} / \mathrm{L} \mathrm{KH}_{2} \mathrm{PO}_{4}, 0.3 \mathrm{~g} / \mathrm{L} \mathrm{MgSO}_{4} \cdot 7 \mathrm{H}_{2} \mathrm{O}$ and $5 \mathrm{~g} / \mathrm{L}$ yeast extract) was used at a final concentration of $20 \%$ total solids (TS) (w/v). Due to the highly inhibitory potential of the slurry, the WIS fraction was also subjected to SSF at $20 \%$ $(\mathrm{w} / \mathrm{v})$ substrate concentration and supplemented with the same nutrients. Since most of the xylose remained in 
the liquid fraction when collecting the WIS fraction, $30 \mathrm{~g} / \mathrm{L}$ xylose were added to the SSF media to enrich the fraction of this sugar and mimic the sugar composition in the slurry.

All SSF experiments were run in triplicate at $150 \mathrm{rpm}, 35^{\circ} \mathrm{C}$ and $\mathrm{pH} 5.5(\mathrm{NaOH} 4 \mathrm{M})$ for $72 \mathrm{~h}$ in $250-\mathrm{mL}$ Erlenmeyer flasks containing $100 \mathrm{~mL}$ of medium. SSF assays were supplemented with $15 \mathrm{FPU} / \mathrm{g}$ substrate of Celluclast 1.5 L (60 FPU/mL) $15 \mathrm{IU} / \mathrm{g}$ substrate of ß-glucosidase NS50010 (900 IU/mL) and $1 \mathrm{~g} / \mathrm{L}$ (dry weight) of either parental or evolved S. cerevisiae F12.

Analytical methods. The chemical composition of the WIS fraction was analyzed by using the standard methods for determination of structural carbohydrates and lignin in biomass (LAP-002, LAP- 003, and LAP019) of the National Renewable Energy Laboratory (NREL). The full description for these methods can be found in the following link [https://www.nrel.gov/bioenergy/biomass-compositional-analysis.html].

Glucose, xylose, xylitol and ethanol were determined and quantified by high-performance liquid chromatography (HPLC) using an Agilent HPLC 1200 Series equipped with a refractive index detector and an Aminex HPX-87H Ion Exclusion column operating at $50{ }^{\circ} \mathrm{C}$ with $5 \mathrm{mM} \mathrm{H}_{2} \mathrm{SO}_{4}(0.6 \mathrm{~mL} / \mathrm{min})$ as elution buffer.

Statistics were performed to estimate the mean and standard deviation during fermentation and SSF assays. Analysis of variance (ANOVA) was used for comparison between assays using the software Statgraphics Centurion XVIII. The level of significance was set at $P<0.05, P<0.01$, and $P<0.001$.

Microarray analysis. Total RNA was extracted from the evolved and parental S. cerevisiae F12 after $4 \mathrm{~h}$ of fermentation in YPXD medium supplemented or not with $40 \%(\mathrm{w} / \mathrm{w})$ insoluble solids and $100 \%(\mathrm{v} / \mathrm{v})$ inhibitor mix. To avoid interferences with RNA extraction method, 4-mm diameter glass beads (Hecht Karl $\left.{ }^{\mathrm{Tx}} 1401 / 4\right)$ were used as insoluble solids instead of pretreated WIS. Cells $(5 \mathrm{~mL})$ were withdrawn, cooled on ice, centrifuged $\left(4000 \mathrm{~g}, 2 \mathrm{~min}, 4^{\circ} \mathrm{C}\right.$ ), frozen in liquid nitrogen and stored at $-80^{\circ} \mathrm{C}$ until further analysis. Trizol reagent (Invitrogen) was used for RNA isolation according to the manufacturer's protocol. Samples were treated with RNase-free DNase I (Qiagen) to prevent DNA contamination. The concentration and purity of RNA was measured using an UV-light Omega spectrophotometer. Furthermore, RNA integrity was determined using the Bioanalyzer 2100 (Agilent) and only samples with 260/280 $>1.8,260 / 230>2.0$, and RNA Integrity Number (RIN) $>8.0$ were subjected to further analysis.

After RNA isolation, samples were treated as explained previously ${ }^{12}$, using the GeneChip ${ }^{\text {ma }}$ Yeast Genome 2.0 Array (Affymetrix ${ }^{\circledast}$ ) to determine gene expression. Raw data were processed with RMA algorithm included in Affymetrix ${ }^{\oplus}$ Expression Console ${ }^{\mathrm{ma}}$ for normalization and gene level analysis. Three microarray experiments corresponding to three independent RNA replicates were processed and analyzed for each experimental condition. Fold changes between experimental conditions were calculated as a quotient between the mean of the gene expression signals. The LIMMA package included in Babelomics software package [http://www.babelomics.org] was used for statistical analysis ${ }^{22}$. Those values with a false discovery rates (FDR) $<0.05$ were considered as significant. Genes with Log2-fold change $>1$ or $<(-1)$ were included for further analysis. Microarray experiments were also analyzed by Piano software [http://biomet-toolbox.chalmers.se] ${ }^{23}$. Differentially expressed genes were identified with an FDR $<0.05$ selection cut-off and the corresponding heat map was simultaneously obtained.

Microarray data were submitted to the NCBI GEO with GSE159167 as accession number [https://www.ncbi. nlm.nih.gov/geo/query/acc.cgi?acc=GSE159167].

Differentially expressed genes were classified by YeastMine according to their main known/proposed functions ${ }^{24}$. In this context, both downregulated and upregulated genes were used to investigate and categorize them according to their biological processes and molecular functions by the gene ontology (GO)-annotations. Finally, network analysis of known/predicted protein-protein interactions was evaluated by STRING software v1 $11^{25}$.

\section{Results and discussion}

Effect of WIS and/or inhibitors on yeast fermentation. This study assessed how the presence of inhibitors and WIS may influence yeast fermentation under the conditions stated in Table 2. As shown in Fig. 1A, no differences were observed in terms of glucose consumption rates or residual glucose in fermentation experiments with $50 \%(\mathrm{v} / \mathrm{v})$ inhibitor mix or $5-10 \%(\mathrm{w} / \mathrm{v})$ of WIS when compared to control assays without insoluble solids and inhibitors. In these cases, no lag phase was detected and glucose was exhausted within the first $5 \mathrm{~h}$ of fermentation. This result agrees with Koppram and co-workers that showed no differences in the consumption of $20 \mathrm{~g} / \mathrm{L}$ glucose when control fermentation (with no WIS in the medium) was compared to fermentations in the presence of $2,5,10$, and $12 \%$ WIS $(\mathrm{w} / \mathrm{w})^{26}$. The presence of $100 \%(\mathrm{v} / \mathrm{v})$ of inhibitor mix reduced, however, the glucose consumption rates, reaching glucose exhaustion at $24 \mathrm{~h}$ (Fig. 1A) and corroborating the well-known effect that high concentration of inhibitors exerts on yeast cells, which in turns hampers glucose utilization ${ }^{27,28}$.

In contrast to glucose conversion, the presence of lignocellulose-derived inhibitors exhibited a strong inhibition effect during the xylose conversion phase (Fig. 1B). In this case, the addition of $50 \%$ and $100 \%$ (v/v) of inhibitor mix resulted in restricted xylose assimilation by cells, which only consumed $18 \%$ and $12 \%$ of the initial xylose concentration, respectively (Table 3 ). The higher susceptibility of xylose fermentation to lignocellulosederived inhibitors compared to that of glucose fermentation has already been shown in several studies ${ }^{29,30}$. Since xylose utilization has been proven to provide less energy in the form of ATP compared to glucose ${ }^{31}$, and response to inhibitors requires high energy levels, the presence of inhibitors may have a stronger effect on yeast when xylose is the utilized carbon source. Furthermore, it is likely that the genetic modifications needed to construct xylose-fermenting yeasts alter their cell metabolic homeostasis affecting the inhibitor tolerance ${ }^{2}$.

By contrast, the presence of $5 \%(\mathrm{w} / \mathrm{w})$ or $10 \%(\mathrm{w} / \mathrm{w})$ WIS slightly increased xylose consumption when compared to control assays (Fig. 1B). Tricarboxylic acids (TCA) cycle was identified as one of the targets of 

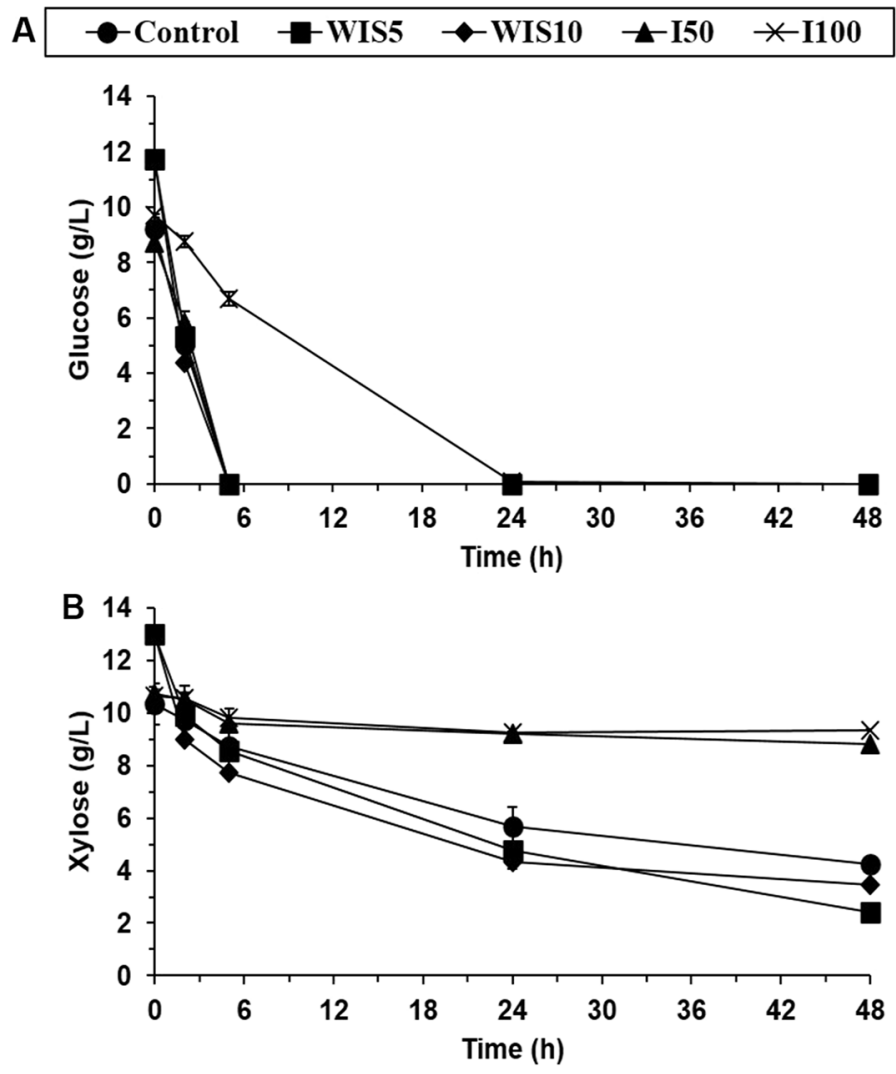

Figure 1. Time-course for (A) glucose and (B) xylose consumption during fermentation assays in presence of different concentrations of WIS and lignocellulose-derived inhibitors.

\begin{tabular}{|c|c|c|c|c|}
\hline Assay & Strain & Glucose consumption (\%) & Xylose consumption (\%) & $\mathrm{Y}_{\mathrm{ETOH}}(\mathrm{g} / \mathrm{g})$ \\
\hline CONTROL & \multirow{9}{*}{ Parental S. cerevisiae F12 } & $100 \pm 0$ & $60 \pm 1$ & $0.28 \pm 0.01$ \\
\hline $\mathrm{I} 50$ & & $100 \pm 0$ & $18 \pm 1$ & $0.22 \pm 0.00$ \\
\hline $\mathrm{I} 100$ & & $100 \pm 0$ & $12 \pm 0$ & $0.19 \pm 0.04$ \\
\hline WIS5 & & $100 \pm 0$ & $82 \pm 3$ & $0.20 \pm 0.00$ \\
\hline WIS10 & & $100 \pm 0$ & $74 \pm 1$ & $0.21 \pm 0.01$ \\
\hline I50_WIS5 & & $100 \pm 0$ & $22 \pm 6$ & $0.22 \pm 0.02$ \\
\hline I50_WIS10 & & $100 \pm 0$ & $22 \pm 1$ & $0.19 \pm 0.01$ \\
\hline I100_WIS5 & & $77 \pm 2$ & $8 \pm 3$ & $0.16 \pm 0.00$ \\
\hline I100_WIS10 & & $18 \pm 4$ & $0 \pm 1$ & $0.05 \pm 0.01$ \\
\hline $\mathrm{I} 100$ & \multirow{3}{*}{ Evolved S. cerevisiae F12 } & $100 \pm 0$ & $64 \pm 1$ & $0.25 \pm 0.04$ \\
\hline WIS10 & & $100 \pm 0$ & $59 \pm 1$ & $0.24 \pm 0.01$ \\
\hline I100_WIS10 & & $100 \pm 0$ & $21 \pm 3$ & $0.24 \pm 0.01$ \\
\hline
\end{tabular}

Table 3. Glucose and xylose consumption and ethanol yields during fermentation assays at different inhibitors and WIS concentrations.

transcriptional regulation to optimize xylose utilization. Thus, intensive TCA cycle was assigned to be important for xylose metabolism in xylose-recombinant $S$. cerevisiae strains ${ }^{32}$. In the same context, regulation of the stress response and amino acid metabolism have been shown as two important strategies for an effective xylose utilization in a recombinant xylose-fermenting S. cerevisiae strain ${ }^{32,33}$. Strikingly, Moreno and co-workers identified amino acids biosynthesis and carboxylic acid metabolic processes among the major overexpressed biological processes in S. cerevisiae F12 grown in glucose media with insoluble solids ${ }^{12}$. Thus, WIS may affect yeast cells by promoting xylose utilization when no other lignocellulose-derived inhibitor is present.

Despite the increase in xylose consumption, ethanol yields in presence of WIS were $0.20-0.21 \mathrm{~g} / \mathrm{g}$. This value was $25-30 \%$ lower than the obtained in control assays $(0.28 \mathrm{~g} / \mathrm{g}$ ) (Table 3$)$. Lower ethanol yields are commonly linked to an increase in xylitol production ${ }^{34}$. Nevertheless, similar xylitol concentrations $(<0.1 \mathrm{~g} / \mathrm{L})$ were found in control and fermentation assays with only WIS. Thus, slight differences in cell growth in presence of WIS or 

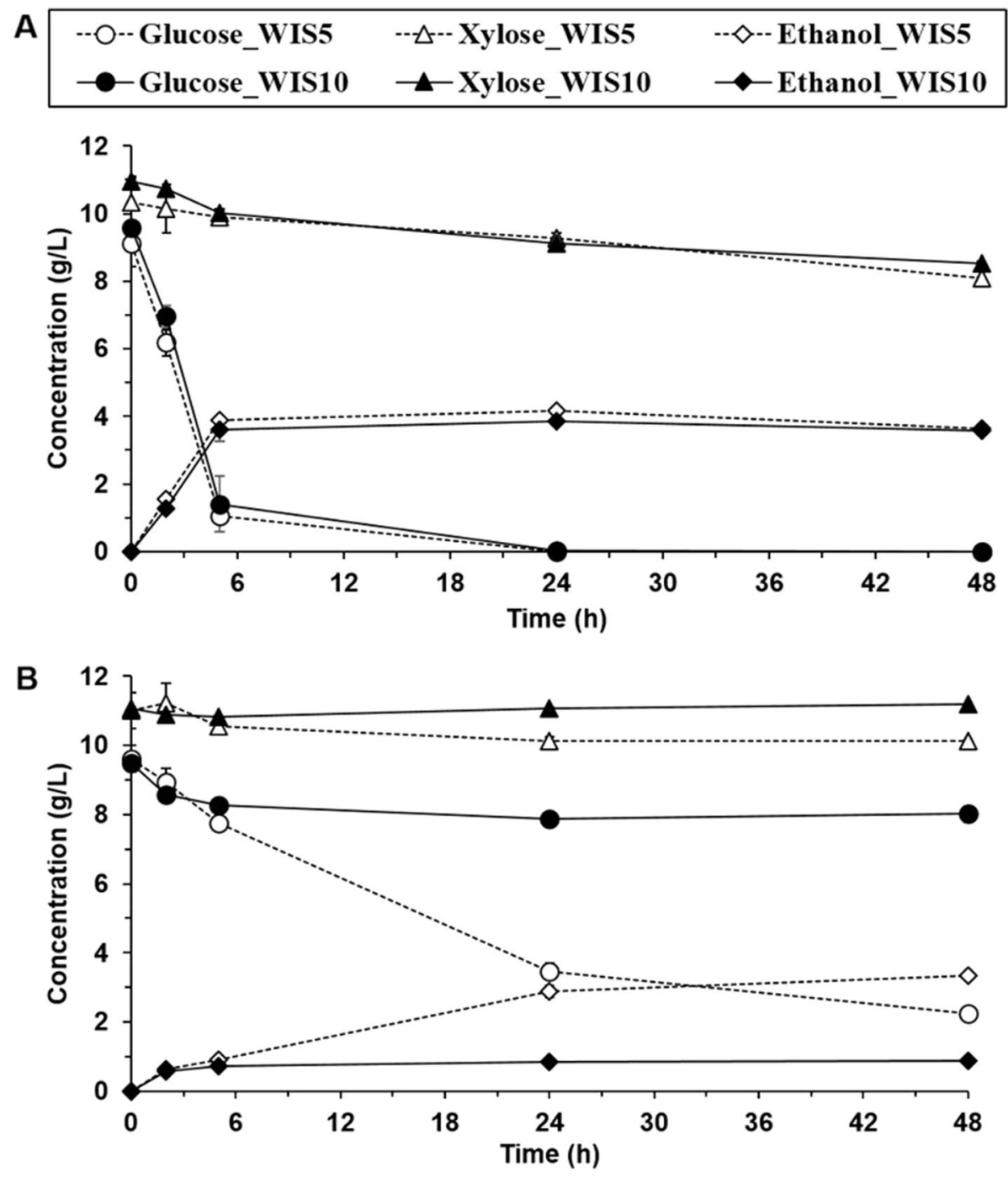

Figure 2. Fermentation assays with (A) $50 \%$ and (B) $100 \%(\mathrm{v} / \mathrm{v})$ inhibitor mix in presence of $5 \%$ and $10 \%$ (w/w) WIS.

redistribution of metabolic fluxes to cope with the challenging conditions imposed by WIS may result in lower ethanol yields.

As mentioned before, Koppram and co-workers ${ }^{26}$ did not observed differences in ethanol yields when adding up to $12 \%(\mathrm{w} / \mathrm{w})$ of WIS to fermentation media with $20 \mathrm{~g} / \mathrm{L}$ glucose, reaching ethanol yields of $0.32 \mathrm{~g} / \mathrm{g}$. However, when adding $40 \%(\mathrm{w} / \mathrm{w})$ and $60 \%(\mathrm{w} / \mathrm{w})$ insoluble solids, Moreno and colleagues ${ }^{12}$ showed a decrease in ethanol yield in glucose media from $0.37 \mathrm{~g} / \mathrm{g}$ without solids to $0.35 \mathrm{~g} / \mathrm{g}$ and $0.22 \mathrm{~g} / \mathrm{g}$, respectively. It is worth mentioning that previous studies only utilized glucose as carbon source. In spite of promoting xylose consumption in presence of $5 \%(\mathrm{w} / \mathrm{w})$ and $10 \%(\mathrm{w} / \mathrm{w})$ of WIS, the reduced ethanol yields obtained in this study indicated that xylose fermentation was more prone to be affected by stressful conditions.

Lower ethanol yields than those obtained for control assays were also found when lignocellulosic inhibitors were present, reaching $0.22 \mathrm{~g} / \mathrm{g}$ and $0.19 \mathrm{~g} / \mathrm{g}$ with $50 \%(\mathrm{v} / \mathrm{v})$ and $100 \%(\mathrm{v} / \mathrm{v})$ of the inhibitor mix, respectively (Table 3). As previously commented, less than $20 \%$ of the initial xylose concentration was consumed by nonevolved yeast cells (Fig. 1B). In addition, when increasing the inhibitor content from $50 \%(\mathrm{v} / \mathrm{v})$ to $100 \%(\mathrm{v} / \mathrm{v})$, the glucose consumption rates decreased by threefold (from $1.8 \mathrm{~g} / \mathrm{L} \mathrm{h}$ to $0.6 \mathrm{~g} / \mathrm{L} \mathrm{h}$ ) at the initial stages of the fermentation process $(5 \mathrm{~h})(\mathrm{Fig} .1 \mathrm{~A})$. This result is indicative of the high inhibitory potential of lignocellulosederived inhibitors, especially during the xylose assimilation phase.

Besides the detrimental effect that the presence of WIS exhibited on ethanol yields in fermentation experiments with $10 \mathrm{~g} / \mathrm{L}$ glucose and $10 \mathrm{~g} / \mathrm{L}$ xylose, the influence that the presence of WIS has on the inhibitory tolerance of S. cerevisiae F12 was also studied. For such a goal, 50\% (v/v) or 100\% (v/v) inhibitor mix were combined with $5 \%(\mathrm{w} / \mathrm{v})$ or $10 \%(\mathrm{w} / \mathrm{v})$ of WIS in different fermentation tests. As it is shown in Fig. 2A, when using $50 \%$ $(\mathrm{v} / \mathrm{v})$ of inhibitor mix, glucose was exhausted within the first $24 \mathrm{~h}$, and $22 \%$ of the xylose was consumed after $48 \mathrm{~h}$ of fermentation. In this case, the ethanol yield was $0.22 \mathrm{~g} / \mathrm{g}$ and $0.19 \mathrm{~g} / \mathrm{g}$ with $5 \%(\mathrm{w} / \mathrm{v})$ and $10 \%(\mathrm{w} / \mathrm{v})$ of WIS, 


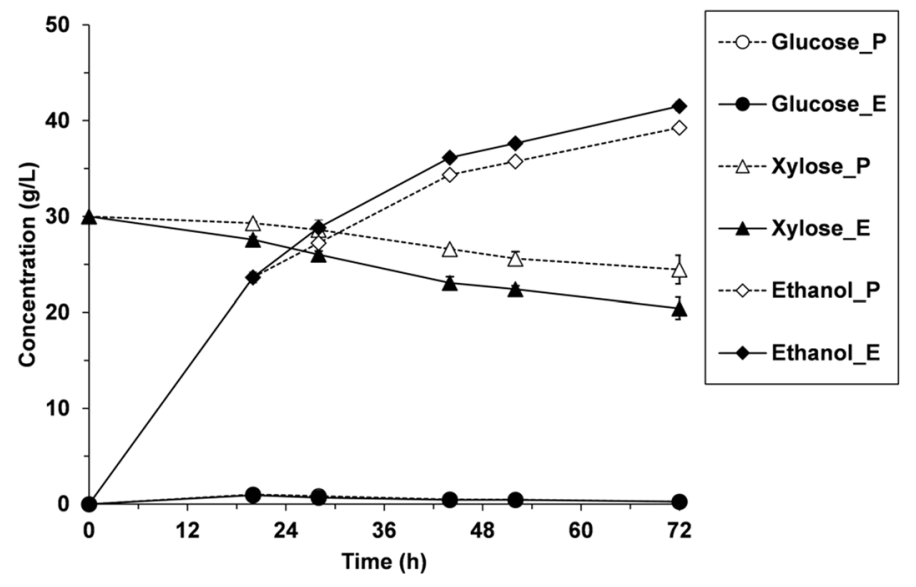

Figure 3. SSF of steam-exploded wheat straw (WIS supplemented with xylose), using the parental (P) and evolved (E) S. cerevisiae F12.

respectively (Table 3 ). These ethanol yields were similar than those obtained when only $50 \%$ (v/v) of inhibitor mix was added (Table 3), indicating that yeast tolerance was not significantly affected by the presence of WIS at low inhibitor concentration. On the other hand, when $100 \%(\mathrm{v} / \mathrm{v})$ of the inhibitor mix was combined with either $5 \%$ or $10 \%(\mathrm{w} / \mathrm{v})$ of WIS neither glucose nor xylose were exhausted in 48 -h long fermentation (Fig. 2B). Furthermore, marked differences were observed in ethanol yield in comparison with only $100 \%(\mathrm{v} / \mathrm{v})$ of the inhibitor mix (Table 3). When $5 \%$ WIS (w/v) were added together with $100 \%(\mathrm{v} / \mathrm{v})$ of the inhibitor mix, about $80 \%$ of the initial glucose and $10 \%$ of the initial xylose were consumed after $48 \mathrm{~h}$ of fermentation, reaching an ethanol yield of $0.16 \mathrm{~g} / \mathrm{g}$. However, $10 \%(\mathrm{w} / \mathrm{v})$ of WIS together with $100 \%(\mathrm{v} / \mathrm{v})$ inhibitor mix resulted in $80 \%$ less ethanol when compared to only $100 \%(\mathrm{v} / \mathrm{v})$ inhibitor mix. The lower ethanol concentrations were directly linked to a completely hampered xylose consumption and to a limited glucose consumption. These results clearly showed a synergistic effect when combining both lignocellulose-derived inhibitors and WIS and pointed out to the presence of WIS as a crucial factor when yeast cells have to deal with high concentrations of inhibitory compounds.

In the present work, an increase in xylose uptake was observed when $50 \%(\mathrm{v} / \mathrm{v})$ of inhibitor mix was combined with WIS compared with only $50 \%(\mathrm{v} / \mathrm{v}$ ) inhibitors (Table 3 ). This result supported the hypothesis that the presence of insoluble solids may promote xylose consumption in absence of biomass degradations compounds or when inhibitors are present at low concentrations. In this sense, Koppram and co-workers ${ }^{26}$ studied the effect of steam-pretreated birch WIS on the glucose consumption and yeast tolerance to either HMF ( $1 \mathrm{~g} / \mathrm{L})$, furfural $(1 \mathrm{~g} / \mathrm{L})$, syringaldehyde $(0.8 \mathrm{~g} / \mathrm{L})$ or acetic acid $(9 \mathrm{~g} / \mathrm{L})$. These authors reported higher glucose uptake rates when low concentrations of these compounds were simultaneously present with WIS compared to those obtained in the absence of solids ${ }^{26}$. In the same study, a proteomic analysis revealed up-regulation of glycolytic enzymes and ATP synthases in the presence of acetic acid and WIS, strongly indicating an increased generation of energy in the presence of both stressors (WIS and inhibitors) which could be the reason for the increased sugar consumption.

The ALE procedure in WIS-rich and inhibitor-rich media (Table 1) resulted in an evolved S. cerevisiae F12 with improved abilities to cope with the combination of both inhibitors and WIS. When compared with the parental strain, a decrease in the xylose consumption was observed when only WIS $(10 \% \mathrm{w} / \mathrm{v})$ was present in the fermentation broth (Table 3). However, in presence of $100 \%(\mathrm{v} / \mathrm{v})$ inhibitor mix, xylose consumption increased from $12 \%$ with parental S. cerevisiae F12 to $64 \%$ with evolved cells which was also translated in an increase of ethanol yield from $0.19 \mathrm{~g} / \mathrm{g}$ to $0.25 \mathrm{~g} / \mathrm{g}$. These results suggest that evolution procedure primarily favored changes to increased tolerance to inhibitors that could be detrimental to cope with the sole presence of insoluble solids. The success of ALE was evident when comparing parental and evolved S. cerevisiae F12 performance at the most challenging conditions (i.e. 100\% (v/v) of inhibitor mix and $10 \%(\mathrm{w} / \mathrm{v})$ of WIS). In this case, parental S. cerevisiae F12 did not consume any xylose and ethanol yield was as low as $0.05 \mathrm{~g} / \mathrm{g}$. On the other hand, xylose consumption and ethanol yield increased to $21 \%$ and $0.24 \mathrm{~g} / \mathrm{g}$, respectively, when using the evolved strain proving the effectiveness of ALE as strategy to increase tolerance to a combination of stressors.

Simultaneous saccharification and fermentation at high substrate loading. Parental $S$. cerevisiae F12 was used in SSF to evaluate its fermentation performance and cell robustness under high substrate loading. When using the whole slurry at a concentration of $20 \% \mathrm{TS}(\mathrm{w} / \mathrm{v})$, no ethanol was produced during SSF processes (data not shown). Although parental cells were able to cope with $100 \%(\mathrm{v} / \mathrm{v})$ inhibitory mix in absence of WIS (Fig. 1), the presence of solids and inhibitors in SSF of slurry led to complete cell inhibition. This fact pointed to a reduced tolerance to inhibitors in presence of high solids content. In this case, the progressive liquefaction of the solids during the first hours of SSF was not sufficient to overcome the effect that WIS had on yeast tolerance to inhibitors. Nevertheless, when using 20\% WIS (w/v) supplemented with xylose (i.e. absence of inhibitors), parental S. cerevisiae F12 was capable of fermenting both glucose and xylose, reaching a maximum ethanol concentration of $39.3 \pm 0.4 \mathrm{~g} / \mathrm{L}$ (Fig. 3). 
A
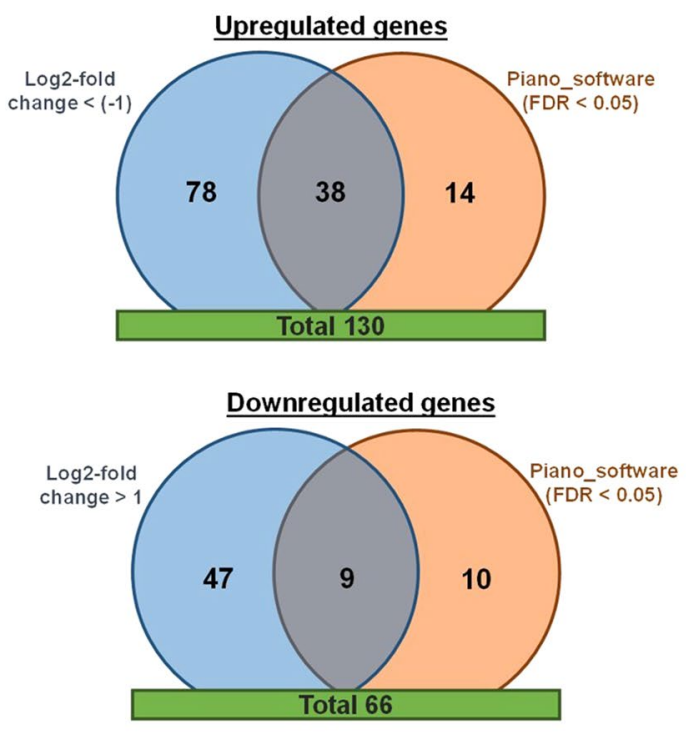

B

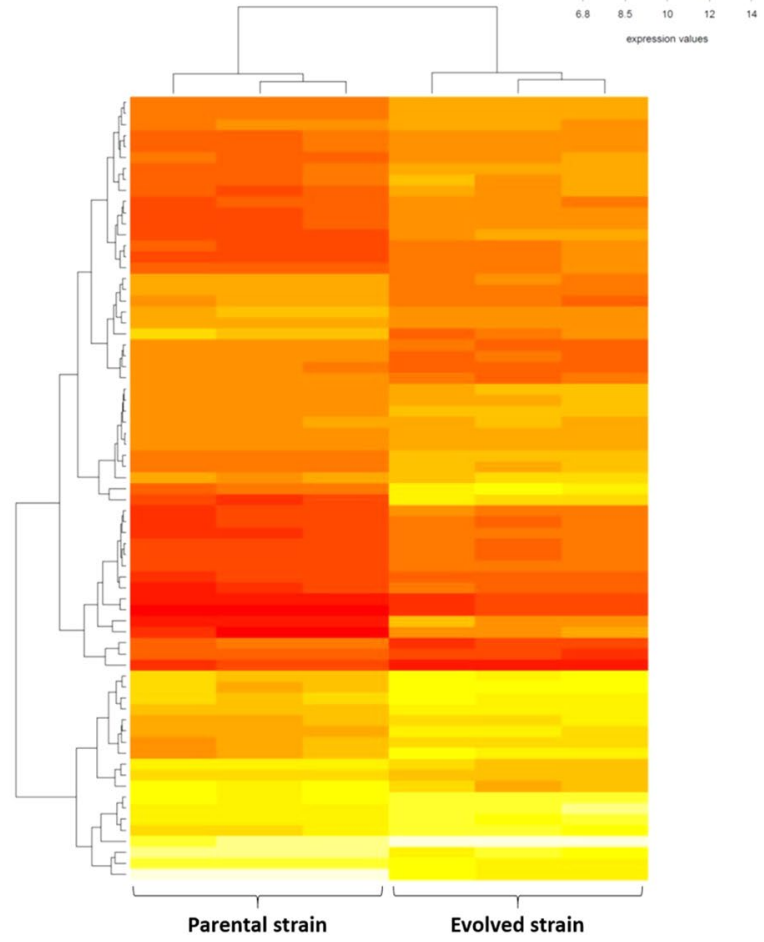

Figure 4. Differential expression analysis between parental and evolved S. cerevisiae F12 in terms of (A) induced and repressed genes and (B) hierarchical clustering. Piano Software [http://biomet-toolbox.chalmers. se].

In SSF from WIS, S. cerevisiae F12 assimilated glucose immediately upon enzymatic hydrolysis, thus maintaining a low glucose concentration during the fermentation process (Fig. 3). In contrast, limited xylose consumption was shown within $72 \mathrm{~h}$ of SSF. Recombinant S. cerevisiae cells use the same transport systems to incorporate both glucose and xylose inside the yeast cell ${ }^{35,36}$. The uptake of xylose through the transport system has been reported to have significantly lower affinities for xylose than for glucose $e^{37}$. In this sense, the xylose uptake is strongly inhibited when glucose is present. This fact is decisive in mixed sugar fermentations with recombinant $S$. cerevisiae strains because this yeast does not utilize xylose unless glucose is significantly depleted. In this case, glucose concentration was below $0.5 \mathrm{~g} / \mathrm{L}$ during SSF process, and the limited xylose consumption could be therefore explained due to the stressful fermentation conditions.

The robustness of the evolved strain was evaluated under the same SSF conditions than the parental strain. Similar to the parental S. cerevisiae F12, the evolved strain was totally inhibited during SSF processes of the whole slurry at 20\% TS (w/v) (data not shown). However, in the SSF from WIS, the evolved strain produced a maximum ethanol concentration of $41.5 \pm 0.5 \mathrm{~g} / \mathrm{L}$, which was $5 \%$ higher $(P<0.01)$ than the obtained by the parental strain (Fig. 3) and represented 50\% of the theoretical maximum ethanol that could be obtained in SSF (yield estimated considering the total glucose and xylose that can be potentially available during SSF process and a maximum sugar-to-ethanol conversion yield of $0.51 \mathrm{~g} / \mathrm{g}$ ). The evolved cells also exhibited improved xylose uptake rates, which increased the xylose consumption by about $10 \%$ ( $32 \%$ of xylose was consumed after $72 \mathrm{~h}$ of SSF). The high xylose:glucose ratio utilized during ALE was decisive for the success of the process since the utilization of xylose as carbon source during the evolution procedure is a key factor to increase the yeast affinity for this sugar. This improved xylose fermenting capacity could be due to improved xylose transport kinetics ${ }^{38,39}$. As a matter of fact, increased expression of hexose transporters was reported in evolved xylose-utilizing yeasts ${ }^{39-41}$, as may be the case for the resulting evolved strain in this study as well.

Differential gene expression of the improved phenotype. A total of 196 genes were found upregulated (130 genes) or downregulated (66 genes) in evolved cells in the presence of both solids $(20 \% \mathrm{w} / \mathrm{w})$ and inhibitors ( $80 \% \mathrm{v} / \mathrm{v}$ of inhibitory mix) (Fig. 4A). These conditions of solids and inhibitors were the most challenging conditions to which cells were evolved in the ALE and thus they were selected for differential gene expression analysis. The differences between parental and evolved cells were also analyzed by hierarchical clustering, which clearly plotted two different groups (Fig. 4B): i) one corresponding to parental cells and ii) another one corresponding to evolved cells. This result supported the differences between S. cerevisiae F12 and the corresponding evolved strain. 


\begin{tabular}{|c|c|c|c|}
\hline Biological Process Enriched & P-value ${ }^{a}$ & Genes & GO term \\
\hline \multicolumn{4}{|l|}{ Upregulated } \\
\hline Cell cycle & $1.99 \mathrm{E}-08$ & $\begin{array}{l}\text { YBR038W, YBR098W, YDL055C, YDL101C, YDL222C, YER095W, YGL021W, YGL116W, YGR044C, YGR108W, } \\
\text { YGR221C, YHR023W, YHR061C, YHR152W, YHR153C, YHR172W, YIL050W, YIL131C, YIL158W, YJR092W, } \\
\text { YKL096W, YML027W, YML052W, YML085C, YMR001C, YMR029C, YMR032W, YMR078C, YMR117C, } \\
\text { YMR199W, YNL196C, YNR009W, YOL069W, YOL132W, YOR026W, YOR301W, YOR315W, YOR372C, } \\
\text { YOR373W, YPL256C, YPL257W, YPR119W }\end{array}$ & GO:0,007,049 \\
\hline Cell wall organization or biogenesis & $1.70 \mathrm{E}-06$ & $\begin{array}{l}\text { YBR038W, YBR067C, YBR076W, YDL055C, YDL222C, YDR261C, YER011W, YHL028W, YHL043W, YHR143W, } \\
\text { YIL123W, YJL158C, YKL096W, YKL096W-A, YKL164C, YKL187C, YML052W, YMR215W, YMR305C, } \\
\text { YNL283C, YOL030W, YOL132W, YOR247W }\end{array}$ & GO: $0,071,554$ \\
\hline \multicolumn{4}{|l|}{ Downregulated } \\
\hline Maltose metabolic process & $2.25 \mathrm{E}-05$ & YBR297W, YBR298C, YBR299W, YDL247W, YGR287C & GO: $0,000,023$ \\
\hline Transport & $6.68 \mathrm{E}-03$ & $\begin{array}{l}\text { YAL067C, YBL042C, YBR068C, YBR069C, YBR298C, YDL247W, YEL065W, YER145C, YGR055W, YGR295C, } \\
\text { YHL035C, YHL040C, YHL047C, YKL220C, YKR093W, YLL038C, YLL048C, YLL051C, YLL052C, YLL053C, } \\
\text { YLR047C, YLR214W, YLR237W, YNL328C, YOR382W, YOR384W, YPL265W }\end{array}$ & GO: $0,006,810$ \\
\hline Homeostatic process & $1.65 \mathrm{E}-02$ & $\begin{array}{l}\text { YEL065W, YER145C, YHL040C, YHL047C, YKL220C, YLL051C, YLR047C, YLR136C, YLR214W, YOR382W, } \\
\text { YOR384W, YPL156C }\end{array}$ & GO: $0,042,592$ \\
\hline
\end{tabular}

Table 4. Upregulated and downregulated biological processes in evolved S. cerevisiae F12 cells. ${ }^{\text {a Multiple }}$ testing was analyzed by Holm-Bonferroni test correction.

\begin{tabular}{|l|l|}
\hline Biological process & Genes $^{\text {a }}$ \\
\hline Upregulated & \multicolumn{2}{|l|}{ Cell cycle process } & $\begin{array}{l}\text { BUB3, CDC5, CDC20, CDC21, CHS2, CLB1, CLB2, CLN1, CLN2, CTF18, DUN1, FDO1, FKH1, } \\
\text { HHO1, HOF1, HTA2, KIN3, MMS4, MYO1, NDD1, NRM1, NUD1, NUF2, PCL7, PLM2, RAD51, } \\
\text { RNR1, SPC24, SPC97, SPO12, TUB1, YOX1 }\end{array}$ \\
\hline Response to stress & ALD2, ALD3, CTT1, FMP45, GRE1, HBT1, HXT5, PAI3, PHM7, SIP18, SPG4, SSA3, TRR2, YEF1 \\
\hline Cell wall organization & CIS3, GAS5, GIC1, SCW10, SIM1, SRL1, TOS1, TOS2, (CWP2, WSC4, WSC2) \\
\hline Sporulation & RME1, SGA1 \\
\hline Cell division & BUD4, RAX1 \\
\hline Mannitol assimilation & DSF1, HXT13 \\
\hline Nitrilase & NIT1, YIL165C \\
\hline Downregulated & \\
\hline Iron ion homeostasis and transport & ARN1, ARN2, ENT4, FIT2, FRE1, FRE2, FRE5, FRE6, FRE8, FTR1, SIT1, TIS11 \\
\hline Ribosome biogenesis, RNA processing & CMS1, ECM2, FAL1, FCF2, HGH1, NOP14, NOP7, ROK1, YCR016W, YNL050C \\
\hline Maltose metabolic process & IMA1, MAL32, MAL31, MAL33 (MPH2) \\
\hline GTP/GMP biosynthetic process & IMD1, IMD2, IMD3 \\
\hline Peptide transport & BAP2, PTR2, (TAT1, MUP1, DIP5) \\
\hline Water transport & AQY2, YLL053C \\
\hline
\end{tabular}

Table 5. STRING analysis of induced and represses genes after evolution of S. cerevisiae F12. ${ }^{\text {a }}$ Upregulated and downregulated genes with similar functions and highlighted by GO analysis are listed in brackets.

Differentially expressed genes (parental $v s$ evolved) were subsequently analyzed by gene ontology (GO) analysis to determine the biological processes induced and repressed. This analysis highlighted cell cycle (e.g., cytokinesis, regulation of cell cycle, reproductive process) and cell wall organization or biogenesis (e.g., fungaltype cell wall organization, sexual sporulation) as major upregulated biological processes, while maltose metabolic process, transport (e.g., ion transport, amino acid transport, water transport) and homeostatic process (e.g., iron ion homeostasis) were the main biological processes downregulated (Table 4). In spite of identifying several biological processes induced and repressed in the improved phenotype, enrichment analysis identified no metabolic pathway statistically upregulated or downregulated. It is also important to remark that a significant number of identified upregulated (53 genes, ca. $40 \%$ ) and downregulated (19 genes, ca. 30\%) genes had an unknown molecular function (Supplementary Table S1). Furthermore, about $90 \%$ of these genes have a Log2-fold change above one order. These results might indicate the potential role of these genes during the cell response to insoluble solids, and therefore, they should be further investigated.

The results obtained by GO analysis regarding induced and repressed biological processes were also supported by the protein-protein interaction networks resulting from STRING analysis. STRING revealed cell cycle process, response to stress and cell wall organization as the main upregulated processes, while homeostasis, ribosome biogenesis and transport were highlighted as major downregulated processes (Table 5, Fig. 5). From these analyses, it is important to highlight the upregulation of genes specifically related with DNA damage and the cell response to stress. These genes included for instance CDC5, CTF18, HTA1, MMS4, PLM2, RNR1, RAD51, DUN1, SSA3, TRR2, CTT1, ALD3, ALD2, PAI3, SIP18, and GRE1. CDC5 is known to prevent the cell-cycle arrest induced by the DNA damage checkpoint, allowing cell division and promoting the adaptation of cells to this cell state ${ }^{42}$. 
INDUCED GENES

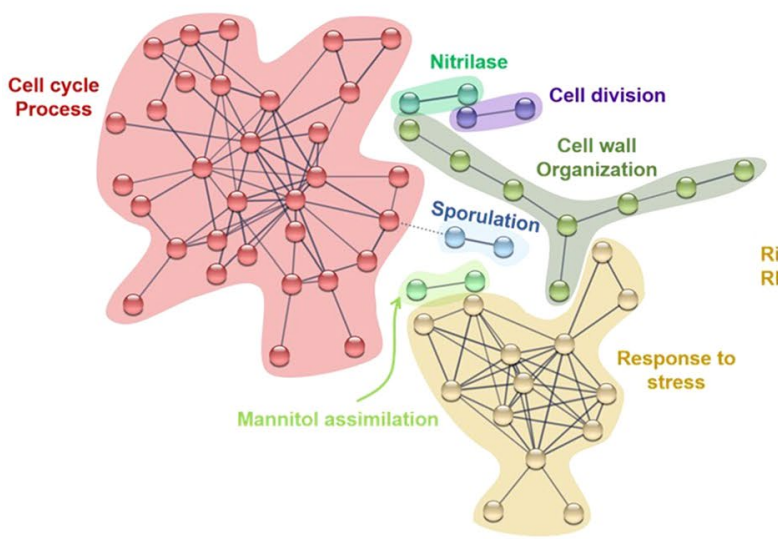

REPRESSED GENES

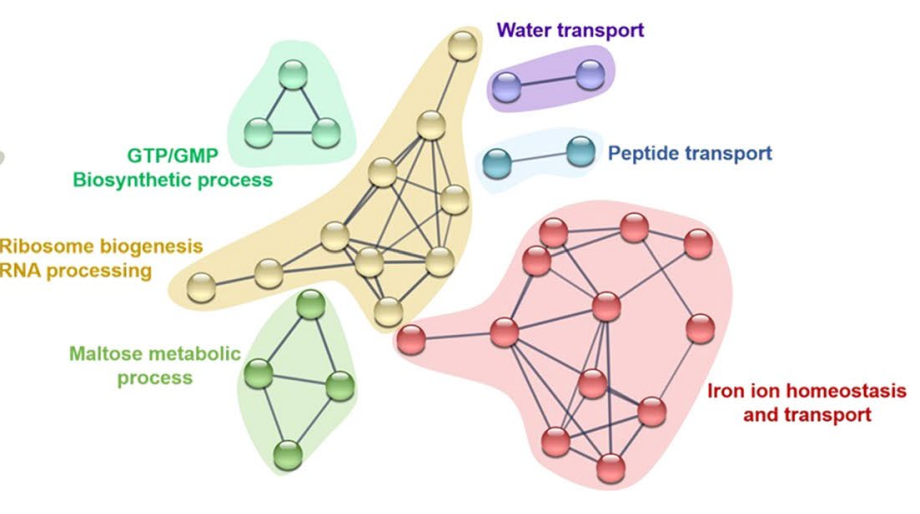

Figure 5. STRING analysis showing protein-protein interactions between induced and repressed genes. STRING software v11 [https://string-db.org/].

Simultaneously, DUN1, CTF18, RNR1 and RAD51 genes were also induced in the evolved S. cerevisiae F12 strain. These genes are also related with the DNA damage replication checkpoint and DNA repair mechanisms ${ }^{43-45}$. The overexpression of these genes might prevent cells from having an excess of mutations during cell adaptation, thus encouraging cell survival. The response to stress was also induced through the overexpression of genes involving the protection against oxidative stress (TRR2, CTT1), heat shock (SSA3, SPG4) and osmotic stress (PAI3), as well as genes related to the general response to stress (GRE1, SIP18, ALD2, ALD3). It is worth highlighting that the overexpression of CTT1 improved xylose utilization in recombinant strains ${ }^{32}$, supporting the overexpression of this gene after ALE that may be responsible of the increased xylose consumption in the evolved S. cerevisiae F12.

Specific genes ( 8 in total) related with cell wall organization were also induced (Tables 4 and 5). Among them, SRL1, CWP2, WSC2 and WSC4 encode important proteins for the stabilization of the cell wall ${ }^{46-48}$. The overexpression of these genes might specifically be related with the yeast response against the stress promoted by solids. The presence of insoluble solids during yeast growth promotes the formation of cavities that cause a change in the external morphology of cells from a round-turgid shape to a highly wrinkled morphology ${ }^{12}$. Overexpression of the aforementioned cell wall proteins might counteract this effect and maintain cell wall integrity under the stress conditions.

Major downregulated biological processes include ribosome biogenesis and RNA processing, as well as the transport of specific molecules including iron, peptides and water (Table 5). Repression of protein synthesis is one of the first cell responses upon stress exposure (heat shock, osmotic and oxidative stress), as it is a highly energy consuming process ${ }^{49,50}$. Nevertheless, although having the general protein synthesis process repressed, cells can simultaneously induce the translation of stress-related genes to face the adverse environmental conditions ${ }^{51}$. This was also the case for the evolved S. cerevisiae F12 in this work. The second main downregulated biological process was transport. Most of the transport-related genes are associated to peptide/amino acid transport and to iron ion transport and homeostasis (Tables 4 and 5). In this work, repression of peptide/amino acid transport genes might be linked with the downregulation of protein biosynthesis upon stress exposure. On the other hand, it is highly remarkable the relatively high number of genes (up to 12 genes) that are involved in iron ion transport and homeostasis, including the transporter-encoding genes FIT2, FTR1, SIT1, ARN1 and ARN2, and genes encoding different ferric reductases (FRE1, FRE2, FRE5, FRE6, FRE8). Iron is an essential element required for different biological processes such as respiration, synthesis of nucleic acids, carbon metabolism, as well as photosynthesis and nitrogen fixation ${ }^{49}$. However, iron may be toxic for cells due to its oxidative capacity in the ferrous form, which increases the importance of having a tight control of the iron metabolism. A high intracellular concentration of reactive oxygen species (ROS) under oxidative stress conditions represents a potential threat since the interaction between ROS and iron may end up in the formation of new hydroxyl radicals with increased prooxidant capacity ${ }^{52}$. The simultaneous presence of both insoluble solids and lignocellulose-derived inhibitors during fermentation processes causes a severe oxidative damage in yeast cells, which greatly increases the intracellular ROS levels ${ }^{12}$. This high ROS concentration might be responsible for repressing the corresponding iron-related genes as a way to reduce the risks associated to a marked oxidative stress. Yeast cells (and other multicellular organisms) usually promote iron depletion to prevent metal toxicity and the irreversible damage under oxidative stress conditions ${ }^{52}$.

Overall, these results clearly show the complex inhibitory environment that cells have to face during lignocellulosic biomass conversion. In response to a single stressor, specific genes and pathways have been identified as key components to increase yeast robustness. For instance, $Z W F 1$ has been identified as a key element during oxidative stress in S. cerevisiae upon exposure to a wide variety of chemical and environmental stress agents $\mathrm{s}^{53}$. During a heat shock, changing ergosterol by fecosterol alters membrane fluidity rendering thermotolerance in yeast $^{54}$. The general response to stress and the cell cycle arrest have been identified as important processes to face a high concentration of insoluble solids ${ }^{12}$. By contrast, in lignocellulose-conversion processes cells must simultaneously deal with a bunch of chemical inhibitors and a high concentration of insoluble solids. To cope with such adverse conditions, this study demonstrate that cells should be capable of maintaining cell membrane 
integrity and preventing oxidative damage. Therefore, upregulation of membrane-related genes (e.g. SRL1, CWP2, WSC2 and WSC4) and induction/repression of genes and pathways involving the oxidative stress and the general response to stress (e.g. CDC5, DUN1, CTT1, GRE1, FTR1, ARN1, FRE1) can be targeted in future studies to evaluate cell robustness in lignocellulose-related bioprocesses.

\section{Conclusions}

The presence of insoluble solids and lignocellulose-derived inhibitors synergistically increased their inhibitory potential exerted on S. cerevisiae F12, especially when using xylose as major carbon source. After subjecting $S$. cerevisiae F12 to an ALE, the resulting evolved cells showed better fermentation performance in terms of higher xylose fermentation efficiency and ethanol yield than the parental strain. Differential gene expression analysis revealed the induction of genes related with cell wall integrity and the response to stress, as well as the repression of protein biosynthesis and the iron transport and homeostasis as main biological processes responsible for the improved phenotype. These results pointed out the necessity of further developing yeast strains less susceptible to the effects caused by all the stress agents present during the conversion of lignocellulosic materials, providing some molecular insights of the mechanism that yeast uses to face these stressors.

Received: 7 July 2021; Accepted: 24 December 2021

Published online: 11 January 2022

\section{References}

1. Passoth, V. \& Sandgren, M. Biofuel production from straw hydrolysates: Current achievements and perspectives. Appl. Microbiol. Biotechnol. 103, 5105-5116. https://doi.org/10.1007/s00253-019-09863-3 (2019).

2. Cunha, J. T., Romani, A., Costa, C. E., Sa-Correia, I. \& Domingues, L. Molecular and physiological basis of Saccharomyces cerevisiae tolerance to adverse lignocellulose-based process conditions. Appl. Microbiol. Biotechnol. 103, 159-175. https://doi.org/10.1007/ s00253-018-9478-3 (2019).

3. Ding, M. Z. et al. Proteomic research reveals the stress response and detoxification of yeast to combined inhibitors. PLoS ONE 7, e43474. https://doi.org/10.1371/journal.pone.0043474 (2012).

4. Guo, Z. \& Olsson, L. Physiological response of Saccharomyces cerevisiae to weak acids present in lignocellulosic hydrolysate. FEMS Yeast Res 14, 1234-1248. https://doi.org/10.1111/1567-1364.12221 (2014).

5. Unrean, P., Gatgens, J., Klein, B., Noack, S. \& Champreda, V. Elucidating cellular mechanisms of Saccharomyces cerevisiae tolerant to combined lignocellulosic-derived inhibitors using high-throughput phenotyping and multiomics analyses. Fems Yeast Res. 18, 1. https://doi.org/10.1093/femsyr/foy106 (2018).

6. Ask, M., Mapelli, V., Höck, H., Olsson, L. \& Bettiga, M. Engineering glutathione biosynthesis of Saccharomyces cerevisiae increases robustness to inhibitors in pretreated lignocellulosic materials. Microb Cell Fact 12, 87. https://doi.org/10.1186/1475-2859-12-87 (2013).

7. Oh, E. J., Wei, N., Kwak, S., Kim, H. \& Jin, Y. S. Overexpression of RCK1 improves acetic acid tolerance in Saccharomyces cerevisiae. J. Biotechnol. 292, 1-4. https://doi.org/10.1016/j.jbiotec.2018.12.013 (2019).

8. Tomás-Pejó, E., Ballesteros, M., Oliva, J. M. \& Olsson, L. Adaptation of the xylose fermenting yeast Saccharomyces cerevisiae F12 for improving ethanol production in different fed-batch SSF processes. J Ind Microbiol Biotechnol 37, 1211-1220. https://doi.org/ $10.1007 / \mathrm{s} 10295-010-0768-8(2010)$.

9. Xiros, C. \& Olsson, L. Comparison of strategies to overcome the inhibitory effects in high-gravity fermentation of lignocellulosic hydrolysates. Biomass Bioenerg. 65, 79-90. https://doi.org/10.1016/j.biombioe.2014.03.060 (2014).

10. Tomás-Pejó, E., Oliva, J. M., Ballesteros, M. \& Olsson, L. Comparison of SHF and SSF processes from steam-exploded wheat straw for ethanol production by xylose-fermenting and robust glucose-fermenting Saccharomyces cerevisiae strains. Biotechnol Bioeng 100, 1122-1131. https://doi.org/10.1002/bit.21849 (2008).

11. Salehi Jouzani, G. \& Taherzadeh, M. J. Advances in consolidated bioprocessing systems for bioethanol and butanol production from biomass: a comprehensive review. Biofuel Res. J. 2, 152-195. https://doi.org/10.18331/brj2015.2.1.4 (2015).

12. Moreno, A. D., González-Fernández, C., Ballesteros, M. \& Tomás-Pejó, E. Insoluble solids at high concentrations repress yeast's response against stress and increase intracellular ROS levels. Sci. Rep. 9, 12236. https://doi.org/10.1038/s41598-019-48733-w (2019).

13. Khatun, M. M., Yu, X., Kondo, A., Bai, F. \& Zhao, X. Improved ethanol production at high temperature by consolidated bioprocessing using Saccharomyces cerevisiae strain engineered with artificial zinc finger protein. Biores. Technol. 245, 1447-1454. https:// doi.org/10.1016/j.biortech.2017.05.088 (2017).

14. Stafford, R. A. in Brewing. Yeast Fermentation Performance. (ed K. Smart) 39-44 (Blackwell Science, 2003).

15. Stenberg, K., Bollók, M., Réczey, K., Galbe, M. \& Zacchi, G. Effect of substrate and cellulase concentration on simultaneous saccharification and fermentation of steam-pretreated softwood for ethanol production. Biotechnol Bioeng 68, 204-210. https://doi. org/10.1002/(sici)1097-0290(20000420)68:2\%3c204::aid-bit9\%3e3.0.co;2-4 (2000).

16. Tomás-Pejó, E., Oliva, J. M., González, A., Ballesteros, I. \& Ballesteros, M. Bioethanol production from wheat straw by the thermotolerant yeast Kluyveromyces marxianus CECT 10875 in a simultaneous saccharification and fermentation fed-batch process. Fuel 88, 2142-2147. https://doi.org/10.1016/j.fuel.2009.01.014 (2009).

17. González-Ramos, D. et al. A new laboratory evolution approach to select for constitutive acetic acid tolerance in Saccharomyces cerevisiae and identification of causal mutations. Biotechnol. Biofuels 9, 1. https://doi.org/10.1186/s13068-016-0583-1 (2016).

18. Moreno, A. D., Carbone, A., Pavone, R., Olsson, L. \& Geijer, C. Evolutionary engineered Candida intermedia exhibits improved xylose utilization and robustness to lignocellulose-derived inhibitors and ethanol. Appl. Microbiol. Biotechnol. 103, $1405-1416$. https://doi.org/10.1007/s00253-018-9528-x (2019).

19. Zeng, W. Y. et al. Comparative transcriptomes reveal novel evolutionary strategies adopted by Saccharomyces cerevisiae with improved xylose utilization capability. Appl. Microbiol. Biotechnol. 101, 1753-1767. https://doi.org/10.1007/s00253-016-8046-y (2017).

20. Oliva-Taravilla, A., Tomás-Pejó, E., Demuez, M., González-Fernández, C. \& Ballesteros, M. Inhibition of cellulose enzymatic hydrolysis by laccase-derived compounds from phenols. Biotechnol Prog 31, 700-706. https://doi.org/10.1002/btpr.2068 (2015).

21. Sonderegger, M. et al. Fermentation performance of engineered and evolved xylose-fermenting Saccharomyces cerevisiae strains. Biotechnol Bioeng 87, 90-98. https://doi.org/10.1002/bit.20094 (2004).

22. Alonso, R. et al. Babelomics 5.0: functional interpretation for new generations of genomic data. Nucl. Acids Res. 43, W117-W121. https://doi.org/10.1093/nar/gkv384 (2015). 
23. Väremo, L., Nielsen, J. \& Nookaew, I. Enriching the gene set analysis of genome-wide data by incorporating directionality of gene expression and combining statistical hypotheses and methods. Nucleic Acids Res. 41, 4378-4391. https://doi.org/10.1093/nar/ gkt111 (2013).

24. Balakrishnan, R. et al. YeastMine-an integrated data warehouse for Saccharomyces cerevisiae data as a multipurpose tool-kit. Database 2012, bar062, doi:https://doi.org/10.1093/database/bar062 (2012).

25. Szklarczyk, D. et al. The STRING database in 2017: quality-controlled protein-protein association networks, made broadly accessible. Nucleic Acids Res. 45, D362-D368. https://doi.org/10.1093/nar/gkw937 (2017).

26. Koppram, R., Mapelli, V., Albers, E. \& Olsson, L. The presence of pretreated lignocellulosic solids from birch during Saccharomyces cerevisiae fermentations leads to increased tolerance to inhibitors - A proteomic study of the effects. PLoS ONE 11, e0148635. https://doi.org/10.1371/journal.pone.0148635 (2016).

27. Almeida, J. R. M., Bertilsson, M., Hahn-Hägerdal, B., Lidén, G. \& Gorwa-Grauslund, M. F. Carbon fluxes of xylose-consuming Saccharomyces cerevisiae strains are affected differently by NADH and NADPH usage in HMF reduction. Appl. Microbiol. Biotechnol. 84, 751-761. https://doi.org/10.1007/s00253-009-2053-1 (2009).

28. Toquero, C. \& Bolado, S. Effect of four pretreatments on enzymatic hydrolysis and ethanol fermentation of wheat straw. Influence of inhibitors and washing. Bioresource Technol. 157, 68-76, doi:https://doi.org/10.1016/j.biortech.2014.01.090 (2014).

29. Ask, M., Bettiga, M., Duraiswamy, V. R. \& Olsson, L. Pulsed addition of HMF and furfural to batch-grown xylose-utilizing Saccharomyces cerevisiae results in different physiological responses in glucose and xylose consumption phase. Biotechnol. Biofuels 6 , 181. https://doi.org/10.1186/1754-6834-6-181 (2013).

30. Martín, C., Marcet, M., Almazan, O. \& Jönsson, L. J. Adaptation of a recombinant xylose-utilizing Saccharomyces cerevisiae strain to a sugarcane bagasse hydrolysate with high content of fermentation inhibitors. Bioresour Technol. 98, 1767-1773. https://doi. org/10.1016/j.biortech.2006.07.021 (2007).

31. Bellissimi, E., Van Dijken, J. P., Pronk, J. T. \& Van Maris, A. J. A. Effects of acetic acid on the kinetics of xylose fermentation by an engineered, xylose-isomerase-based Saccharomyces cerevisiae strain. FEMS Yeast Res. 9, 358-364. https://doi.org/10.1111/j. 1567-1364.2009.00487.x (2009).

32. Cheng, C. et al. Association of improved oxidative stress tolerance and alleviation of glucose repression with superior xyloseutilization capability by a natural isolate of Saccharomyces cerevisiae. Biotechnol. Biofuels 11, 28. https://doi.org/10.1186/s13068018-1018-y (2018).

33. Feng, X. \& Zhao, H. Investigating host dependence of xylose utilization in recombinant Saccharomyces cerevisiae strains using RNA-seq analysis. Biotechnol. Biofuels 6, 96. https://doi.org/10.1186/1754-6834-6-96 (2013).

34. Krahulec, S., Klimacek, M. \& Nidetzky, B. Analysis and prediction of the physiological effects of altered coenzyme specificity in xylose reductase and xylitol dehydrogenase during xylose fermentation by Saccharomyces cerevisiae. J. Biotechnol. 158, 192-202. https://doi.org/10.1016/j.jbiotec.2011.08.026 (2012).

35. Chu, B. C. H. \& Lee, H. Genetic improvement of Saccharomyces cerevisiae for xylose fermentation. Biotechnol. Adv. 25, 425-441. https://doi.org/10.1016/j.biotechadv.2007.04.001 (2007).

36. Jojima, T., Omumasaba, C. A., Inui, M. \& Yukawa, H. Sugar transporters in efficient utilization of mixed sugar substrates: Current knowledge and outlook. Appl. Microbiol. Biotechnol. 85, 471-480. https://doi.org/10.1007/s00253-009-2292-1 (2010).

37. Subtil, T. \& Boles, E. Competition between pentoses and glucose during uptake and catabolism in recombinant Saccharomyces cerevisiae. Biotechnol. Biofuels 5, 14. https://doi.org/10.1186/1754-6834-5-14 (2012).

38. García Sánchez, R. et al. Improved xylose and arabinose utilization by an industrial recombinant Saccharomyces cerevisiae strain using evolutionary engineering. Biotechnol. Biofuels 3, 13. https://doi.org/10.1186/1754-6834-3-13 (2010).

39. Kuyper, M. et al. Evolutionary engineering of mixed-sugar utilization by a xylose-fermenting Saccharomyces cerevisiae strain. FEMS Yeast Res. 5, 925-934. https://doi.org/10.1016/j.femsyr.2005.04.004 (2005).

40. Moyses, D. N., Reis, V. C., de Almeida, J. R., de Moraes, L. M. \& Torres, F. A. Xylose fermentation by Saccharomyces cerevisiae: Challenges and prospects. Int. J. Mol. Sci. 17, 207. https://doi.org/10.3390/ijms17030207 (2016).

41. Vilela, L. F. et al. Enhanced xylose fermentation and ethanol production by engineered Saccharomyces cerevisiae strain. AMB Express 5, 16. https://doi.org/10.1186/s13568-015-0102-y (2015).

42. Vidanes, G. M. et al. CDC5 Inhibits the hyperphosphorylation of the checkpoint cinase Rad53, leading to checkpoint adaptation. PLoS Biol. 8, e1000286. https://doi.org/10.1371/journal.pbio.1000286 (2010).

43. Naiki, T., Kondo, T., Nakada, D., Matsumoto, K. \& Sugimoto, K. Chl12 (Ctf18) forms a novel replication factor C-related complex and functions redundantly with Rad24 in the DNA replication checkpoint pathway. Mol. Cell. Biol. 21, 5838. https://doi.org/10. 1128/MCB.21.17.5838-5845.2001 (2001)

44. Yam, C. Q. X., Chia, D. B., Shi, I., Lim, H. H. \& Surana, U. Dun1, a Chk2-related kinase, is the central regulator of securin-separase dynamics during DNA damage signaling. Nucl. Acids Res. 48, 6092-6107. https://doi.org/10.1093/nar/gkaa355 (2020).

45. Zhou, Z. \& Elledge, S. J. DUN1 encodes a protein kinase that controls the DNA damage response in yeast. Cell 75, $1119-1127$. https://doi.org/10.1016/0092-8674(93)90321-G (1993).

46. Hagen, I. et al. Sed1p and Srllp are required to compensate for cell wall instability in Saccharomyces cerevisiae mutants defective in multiple GPI-anchored mannoproteins. Mol. Microbiol. 52, 1413-1425. https://doi.org/10.1111/j.1365-2958.2004.04064.x (2004).

47. Lesage, G. \& Bussey, H. Cell wall assembly in Saccharomyces cerevisiae. Microbiol. Mol. Biol. Rev. 70, 317-343. https://doi.org/10. 1128/MMBR.00038-05 (2006).

48. Zu, T., Verna, J. \& Ballester, R. Mutations in WSC genes for putative stress receptors result in sensitivity to multiple stress conditions and impairment of Rlm1-dependent gene expression in Saccharomyces cerevisiae. Mol. Genet. Genom. 266, 142-155. https://doi. org/10.1007/s004380100537 (2001).

49. Romero, A. M., Ramos-Alonso, L., Alepuz, P., Puig, S. \& Martínez-Pastor, M. T. Global translational repression induced by iron deficiency in yeast depends on the Gen2/eIF2 a pathway. Sci. Rep. 10, 233. https://doi.org/10.1038/s41598-019-57132-0 (2020).

50. Yamamoto, Y. \& Izawa, S. Adaptive response in stress granule formation and bulk translational repression upon a combined stress of mild heat shock and mild ethanol stress in yeast. Genes Cells 18, 974-984. https://doi.org/10.1111/gtc.12090 (2013).

51. Garre, E., Pelechano, V., Sánchez Del Pino, M., Alepuz, P. \& Sunnerhagen, P. The Lsm1-7/Pat1 complex binds to stress-activated mRNAs and modulates the response to hyperosmotic shock. PLoS genetics 14, e1007563-e1007563, doi:https://doi.org/10.1371/ journal.pgen.1007563 (2018)

52. Castells-Roca, L., Mühlenhoff, U., Lill, R., Herrero, E. \& Bellí, G. The oxidative stress response in yeast cells involves changes in the stability of Aft1 regulon mRNAs. Mol. Microbiol. 81, 232-248. https://doi.org/10.1111/j.1365-2958.2011.07689.x (2011).

53. Heinisch, J. J., Knuesting, J. \& Scheibe, R. Investigation of heterologously expressed glucose-6-phosphate dehydrogenase genes in a yeast $z w f 1$ deletion. Microorganisms 8, 546. https://doi.org/10.3390/microorganisms8040546 (2020).

54. Caspeta, L. et al. Altered sterol composition renders yeast thermotolerant. Science 346(6205), 75-78. https://doi.org/10.1126/scien ce.1258137 (2014)

\section{Acknowledgements}

Authors thank Professor Lisbeth Olsson (Chalmers University of Technology) for kindly providing S. cerevisiae F12 strain. 


\section{Author contributions}

A.D.M. and E.T.P. performed and coordinated the study, analyzed the data, and prepared the manuscript. C.G.F. contributed to coordinate the study and prepare the manuscript.

\section{Funding}

Elia Tomás-Pejó acknowledges the grant RYC2019-027773-I funded by MCIN/AEI/10.13039/501100011033 and by "ESF Investing in your future". Comunidad de Madrid provided financial support through project ALGATECCM (P2018/BAA-4532).

\section{Competing interests}

The authors declare no competing interests.

\section{Additional information}

Supplementary Information The online version contains supplementary material available at https:/doi.org/ 10.1038/s41598-021-04554-4.

Correspondence and requests for materials should be addressed to E.T.-P.

Reprints and permissions information is available at www.nature.com/reprints.

Publisher's note Springer Nature remains neutral with regard to jurisdictional claims in published maps and institutional affiliations.

(c) (i) Open Access This article is licensed under a Creative Commons Attribution 4.0 International License, which permits use, sharing, adaptation, distribution and reproduction in any medium or format, as long as you give appropriate credit to the original author(s) and the source, provide a link to the Creative Commons licence, and indicate if changes were made. The images or other third party material in this article are included in the article's Creative Commons licence, unless indicated otherwise in a credit line to the material. If material is not included in the article's Creative Commons licence and your intended use is not permitted by statutory regulation or exceeds the permitted use, you will need to obtain permission directly from the copyright holder. To view a copy of this licence, visit http://creativecommons.org/licenses/by/4.0/.

(C) The Author(s) 2022 